\title{
Mitochondrial-targeted Expression of orf456 Causes Male Sterility in Chinese Cabbage (Brassica rapa L.)
}

\author{
Li Liu ${ }^{1}$, Yeong Deuk Jo ${ }^{1}$, Won-Hee Kang ${ }^{1}$, Dosun $\mathrm{Kim}^{2}$, and Byoung-Cheor Kang ${ }^{1}$ * \\ ${ }^{1}$ Department of Plant Science and Plant Genomics and Breeding Institute, Seoul National University, Seoul 151-921, Korea \\ ${ }^{2}$ National Institutes of Horticultural and Herbal Science, Suwon 440-706, Korea
}

\begin{abstract}
Cytoplasmic male sterility (CMS) is a phenomenon specific to plant reproduction that has been extensively exploited for hybrid seed production. Orf456 was previously identified as a candidate gene mediating male sterility in pepper. To gain further insight of this candidate gene, we carried out experiments to transform Chinese cabbage (Brassica rapa $\mathrm{L}_{\text {.) }}$. About $30 \mathrm{~T}_{1}$ transgenic lines were obtained and approximately $50 \%$ of $\mathrm{T}_{1}$ transgenic Chinese cabbage lines showed male-sterility. To evaluate pollen viability, three different approaches including plasmolysis test, staining pollen and in vitro germination assay were used. Analysis of the CMS transgenic lines showed that trasgenic Chinese cabbages produced aberrant pollen development while some were unable to produce pollen. In conclusion, the mitochondrial orf456 gene could induce partial male sterility in transgenic Chinese cabbage. Nevertheless, how the orf456 gene precisely functions to induce male sterility and its biochemical function remains to be discovered.
\end{abstract}

Keywords Chinese cabbage (Brassica rapa L.), Cytoplasmic male sterility, orf456, Molecular breeding

\section{INTRODUCTION}

Cytoplasmic male sterility (CMS) is a maternally inherited condition in which a plant is unable to produce viable pollen (Gómez 1999). Since the first documentation of male sterility by Joseph Gottlieb Kölreuter, who observed anther abortion within species and specific hybrids, cytoplasmic male sterility has been identified in over 150 plant species (Schnabel and Wise 1998; Hanson and Bentolila 2004; Chowdhury and Ahmad 2010).

CMS obviously reflects a conflict between the maternally inherited mitochondrial genome, which induces male sterility without affecting the overall fitness of the plant. CMS can occur at different stages during reproductive developments (Linke and Börner 2005; Chase 2007). It is generally considered that CMS is caused by the rearrangement of mitochondrial genomes, which, in many cases, is attributed to the generation of novel Open Reading Frames (ORF) (Yang and Zhang 2007). In a number of cases, transcripts originating from these altered open reading frames are translated into unique proteins that appear to interfere with mitochondrial function and pollen development (Yamamoto 2008). CMS anther degeneration is probably caused by dysfunction of tapetum or vacuolation of tapetum, PMCs, and microspores (Shi et al. 2010). Most studies have been performed on vegetative tissues that express the CMS- associated proteins; however, biochemical and physiological studies have provided some clues to the disruption in aborted pollen development (Shi et al. 2010). Nevertheless, the precise action of a mitochondrial locus that confers male sterility has not been determined definitively for any species.

The Brassica family contains about 3,500 species and 350 genera and is one of the economically most important plant families (Rich 1991; Quijada et al. 2007). Brassica rapa $(2 \mathrm{n}=20, \mathrm{AA})$ is a diploid crop in this family, which is currently widely cultivated in China, Japan, Korea, India, Canada, and Europe to produce vegetable, oilseed and fodder (Hirai and Matsumoto 2007; Li et al. 2013). Since Ogura (1968) first reported the CMS line of radish, a

Received Jun 20, 2013; Revised Jun 24, 2013; Accepted Jun 27, 2013; Published June 30, 2013

*Corresponding author Byoung-Cheorl Kang, bk54@snu.ac.kr, Tel: +82-2-880-4563, Fax: +82-2-873-2056 
number of $F_{1}$ hybrid cultivars have been developed using the Ogura CMS system in many economically important Brassica family crops. Despite many studies on CMS, researchers and breeders have made efforts to search for new sources of CMS in breeding.

In the previous studies, a mitochondrial atp6 gene was identified as a CMS assoicate gene (Kim et al. 2006a; Kim et al. 2001). Then the second CMS-associated gene orf 456 was identified through analysis DNA and RNA blot hybridization between male fertile and CMS lines of chili pepper (Kim et al. 2007). The gene was located at the 3 '-end of the coxII gene in CMS pepper. Later, it was shown that overexpression of orf 456 severely induced male sterility in Arabidopsis (Kim et al. 2007). To investigate the functional role of the ORF456 protein in B. rapa, we carried out transformation of $B$. rapa with orf 456 fused to a mitochondrion-targeted coxIV gene.

\section{MATERIALS AND METHODS}

\section{Plant materials}

The wild-type Seoul Baechu (B. rapa), were kindly provided by D.H. Kim (Seoul National University, Korea).

Plant chimeric gene construction and transformation

Orf456 and Cox IV were cloned into the plant transformation vector pMDC32, which contains $35 \mathrm{~S}$ promoter. Purified a)

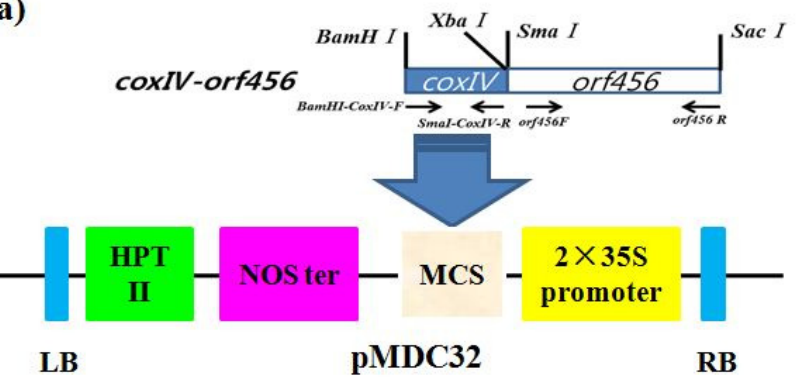

d)

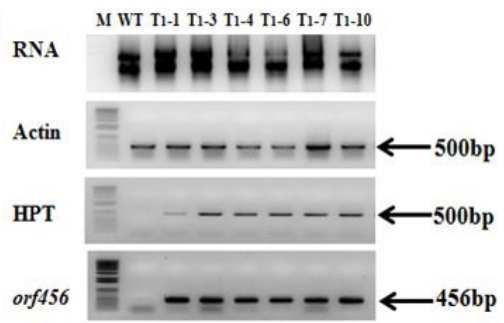

b)

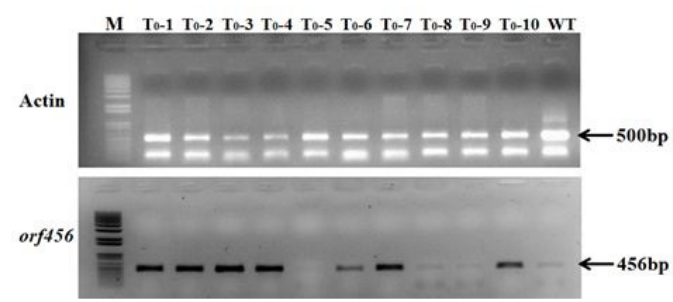

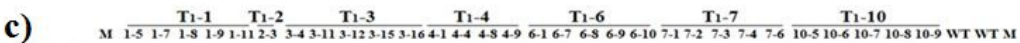

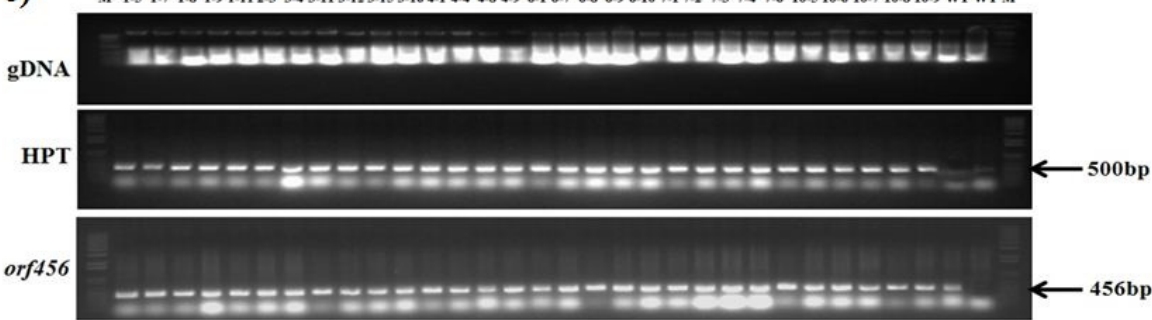

Fig. 1. Orf456 chimeric gene construct and transformation in B.rapa. a) Schematic diagram illustrating the construction and ligation of orf456 and cox $I V$ into plant transformation vector, pMDC32, driven by the 35S promoter. b) Polymerase chain reaction (PCR) analysis of chimeric gene genetically modified situation in $\mathrm{T}_{0}$ individual transgenic $B$. rapa plants. Actin was used as internal control to probe Chinese cabbage gDNA quality. c) Polymerase chain reaction (PCR) analysis of chimeric gene genetically modified situation in $\mathrm{T}_{1}$ individual transgenic $B$. rapa plants. HPT was hygromycin $\mathrm{B}$, an antibiotic produced by the bacterium Streptomyces hygroscopicus. d) RNA and RT-PCR analysis of $\mathrm{T}_{1}$ individual transgenic B. rapa lines. 
plasmid DNA of each pMDC32 construct (Fig. 1a) was electroporated into Agrobacterium tumefaciens LBA4404. The presence and stability of the transgenes was verified by PCR (Fig. 1b, c, d). Chinese cabbage cultivar 'Seoul' was transformed using leaf disk method at National Institute of Horticultural and Herbal Science. For the $\mathrm{T}_{1}$ selection, a hygromycin $\left(15 \mathrm{mg} \mathrm{mL}^{-1}\right)$-containing Murashige and Skoog (50\%) medium (Sigma, USA) was used.

\section{Growth conditions and sampling}

Transgenic Chinese cabbage lines was sterilized by $70 \%$ ethyl alcohol and 50\% Clorox and germinated on MS media (Sigma, USA) containing Hygromycin B (HTP) (Sigma, USA). After 2 weeks, the seedlings were transplanted to soil and were cultured in a growth chamber ( 2 or 3 weeks). When the fifth leaf was fully expanded, the seedlings were exposed to a $4^{\circ} \mathrm{C}$ low temperature in a period of 20 to 30 days to achieve a complete vernalization for bolting (National Institute of Horticultural and Herbal Science, Suwon, Korea).

Fresh buds and anther were collected and fixed in Carnoy's Fluid (a fixative composed of $60 \%$ ethanol, 30\% chloroform and $10 \%$ glacial acetic acid) and samples were stored in a refrigerator at $4^{\circ} \mathrm{C}$. Fresh pollen of the orf 456 transformants and wild-type line were collected by shaking a flower on a clean sheet of paper, pouring the pollen into a $1.5 \mathrm{~mL}$ microcentrifuge tube with $0.5 \mathrm{~mL} 70 \%(\mathrm{v} / \mathrm{v})$ ethanol and stored at $4^{\circ} \mathrm{C}$.

\section{DNA and RNA extraction and RT-PCR}

Genomic DNA was extracted from young leaves using hexadecyltrimethylammonium bromide (CTAB) method (Prince et al. 1997). Total RNA was extracted from young flowers buds of $T_{1}$ transgenic plants using the TRIzol reagent (Invitrogen, Carlsbad, CA, USA) according to the manufacturer's instructions. Total RNA was then treated with RNase-free DNase I (Ambion, USA) to remove possible contamination of genomic DNA for RT-PCR. Total RNA $(2 \mu \mathrm{g})$ was used for first-strand cDNA synthesis using M-MLV reverse transcriptase (Invitrogen, USA). For PCR analysis of orf 456, the forward primer 5'-ATGC CCAAAAGTCCCATGTA-3' and the reverse primer 5'-
TTACTCGGTTGCTCCATTGTTT-3' were used. For coxIV, the forward primer 5'-GGATCCATGTTGTCACTACG TCAATCTATAAGA-3' and the reverse primer 5'-CCCG GGACCCTCTTTAGCACCAGGACC-3' were used. For HPT, the forward primer 5'-CCTGAACTCACCGCGACG-3' and the reverse primer 5'-AAGACCAATGCGGAGCATAT -3 ' were used. Brassica actin was used as control.

\section{Pollen viability test}

The plasmolysis test was performed to evaluate pollen viability. Fresh pollen of the orf456 transformants and wild-type line were collected and added with $20 \mu \mathrm{L}$ of hypertonic solution ( $25 \%$ glycerol) on glass slides. Pollen were stained with $1 \%$ aceto-carmine (Nassar et al. 2000) and iodine (Jeffrey 2004) to detect cytoplasmic content. After 10 min incubation at room temperature, stained pollen were observed under a light microscope. In vitro germination assays were performed to determine the germination ability of pollen. Growth medium contained $10 \%$ sucrose, $0.01 \%$ boric acid ( $\mathrm{pH} 6.8$ ). After incubation at $20-25^{\circ} \mathrm{C}$ for about $4 \mathrm{hrs}$, the solution has been covered with a glass cover slip and photographed.

\section{RESULTS}

\section{Chimeric gene construction and transformation}

In the previous study, a CMS-associated gene, orf456 was found at the 3' -end of the coxII gene, which was identified as a strong candidate for determining the malesterile phenotype in pepper (Kim et al. 2007). When this gene was ectopically expressed in Arabidopsis, transgenic plants showed abnormal pollen development and sterility. To test if transgenic expression of the orf456 gene can induce male sterility in Brassica, transgenic plants were developed. To transform B. rapa, a chimeric gene was constructed by fusing orf456 gene with a mitochondrial transit peptide sequence (54 codons) of the nuclear coxIV gene. The orf456 gene was amplified from CMS lines of chili pepper and ligated after the mitochondrial-targeting sequence of coxIV. Subsequently the chimeric gene has been ligated to the plant transformation vector, pMDC32, 
driven by the $35 \mathrm{~S}$ promoter. The schematic structure of the chimeric orf456 gene is shown in Fig. 1a. The constructs were introduced into B. rapa 'Seoul Baechu'. Putative transgenic plants were selected by PCR and RT-PCR (Fig. $1 \mathrm{~b}, \mathrm{c}, \mathrm{d})$ and $10 \mathrm{~T}_{0}$ plants exhibiting male sterility were obtained (Fig. 1b). We used the orf456 gene as a marker to prove that this gene was inherited and could be expressed in $\mathrm{T}_{1}$ transgenic (Fig. 1c, d). The male-sterile phenotype was shown to be genetically transmitted to the $T_{0}$ and $T_{1}$ generation associated with orf456 expression in B. rapa (Fig. 1b, c). All the 10 male-sterile $T_{1}$ plants expressed the orf456 gene, and all the 30 male-fertile $\mathrm{T}_{1}$ plants lacked orf456 expression in B. rapa.

\section{Phenotypes of orf456 transformants}

Morphological characteristics of transgenic plants harboring the chimeric orf456 gene were evaluated. The vegetative growth of transgenic $B$. rapa was similar to that of wild-type plants, but their reproductive characteristics differed in numerous ways including delays in bolting and flowering time (Fig. 2a), aborted buds structures at the basal part of the raceme (Fig. 2b), aberrant floral organ
(Fig. 2c). Comparison of silique and pod among wild-type and transgenic $B$. rapa revealed the inability of transgenic plants to seed-set at an early developmental stage (Fig. 2d, e). The seed size and weight also differed between wildtype and transgenic B. rapa. The former showed spherical, brown and glossy seeds, while the latter showed shriveled shape of seeds, which implies embryo hypoplasia (Fig. 2f). When the transgenic plants were cross-pollinated with wild-type plants, seed-setting occurred indicating normal pistil fertility (Fig. 2e).

Additionally, four types of aberrant flowers were observed in transgenic plants; flowers with less or more than six normal stamens (Fig. 2c-1), flowers with degenerative stamens devoid of pollen (Fig. 2c-2), one flower with several styles and petal-like sepal (Fig. 2c-3), and two or more coalescing flowers (Fig. 2c-4, c-5). These phenotypes of aberrant floral organs in transgenic $B$. rapa are similar with others studies (Yang et al. 2010 and Kim et al. 2007).

\section{Pollen viability of transgenic lines}

Pollen of the orf456 transformants and wild-type B. rapa at the anther dehiscent stage were fixed and observed under a)
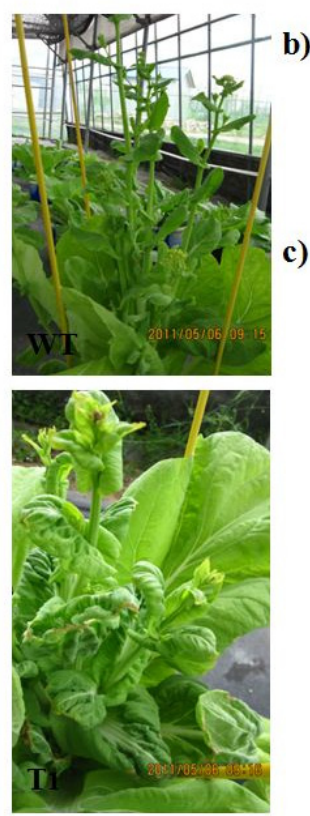

\section{b)}
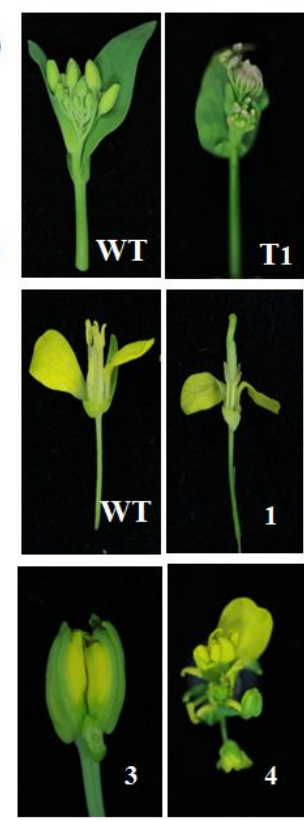

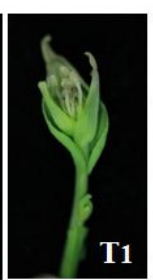

d)

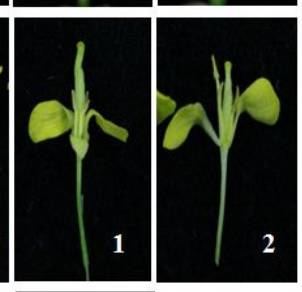

f)
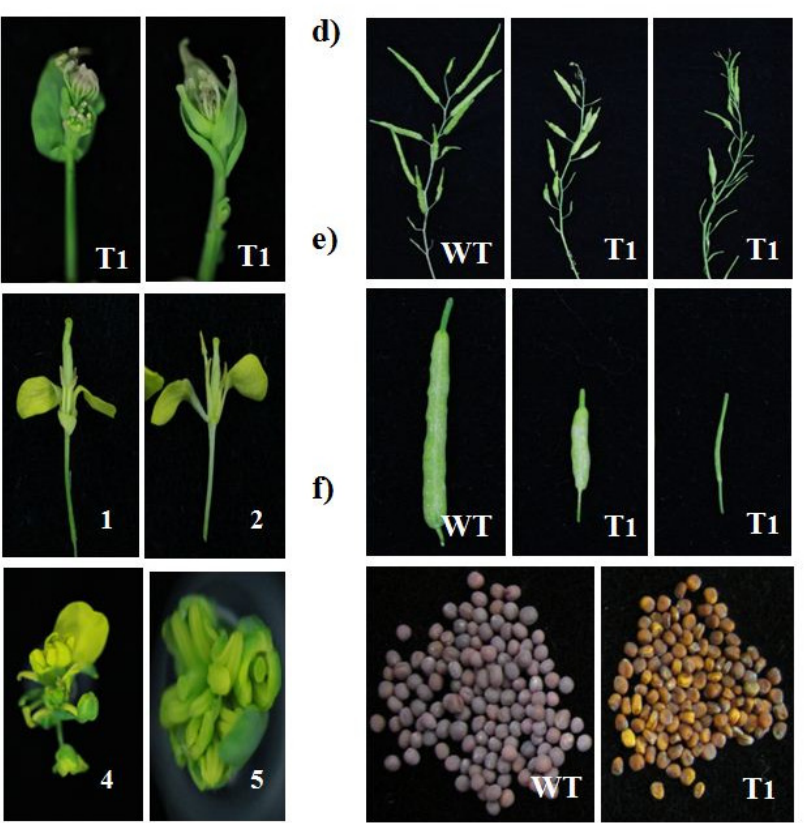

Fig. 2. Phenotypes of wild-type and orf456 transformants. The morphological characters were observed in transgenic plants in which the chimeric orf456 gene was expressed. Results suggested that orf456 expression may have functioned in the various reproductive growth performance of transgenic $B$. rapa lines. a) Transgenic $\mathrm{T}_{1}$ B. rapa plants, b) buds, c) blossoms, d) siliques, e) pods, f) seeds. 
a light microscope (LM). We used three different approaches to estimate pollen viability: plasmolysis test, staining pollen with dyes and in vitro germination assay.

The plasmolysis test was performed to check the intactness of pollen. When placed in hypertonic ( $25 \%$ glycerol) solution, pollen of orf456-transformed B. rapa burst within 10-15 min (Fig. 3b), while the wild-type pollen grains remained intact even after $24 \mathrm{~h}$ (Fig. 3a). This indicates that the pollen of the orf456-transformed B. rapa was undergoing ateliosis. Pollen staining was used to determine enzymatic activity and membrane integrity of pollen. The morphology of acetocarmine and iodine-stained pollen was altered in transgenic B. rapa (Fig. 3b). This indicates the different pollen activity taking place in transgenic plants. In vitro germination assays determine the actual germination ability of pollen. After $4 \mathrm{hrs}$ incubation at $20-25^{\circ} \mathrm{C}$, the pollen grain is slightly swollen, with one of the three pores (furrows) open and the pollen tube emerging. Pollens from wild-type $B$. rapa produced pollen tubes, whereas those of transgenic plant bursted hence no pollen tube was growing (Fig. 3c).

\section{Statistical analyses of pollen abortion phenotypes in the CMS lines}

To confirm the function of orf 456 in producing a malesterile phenotype, two independent tests were conducted. We randomly selected 7 out of 10 transgenic $\mathrm{T}_{0}$ lines that contained coxIV-orf456, and obtained $\mathrm{T}_{1}$ transgenic plants. The malformed pollen ratio of 15 plants lower than $10 \%$, which showed a male fertility (Table 1 ). We analyzed the aberrant flowers ratio and malformed pollen ratio in $\mathrm{T}_{1} B$. rapa lines. The result indicated that approximately $50 \% \mathrm{~T}_{1}$ B. rapa exhibited the male-sterile malformed blossom and $33.3 \% \mathrm{~T}_{1}$ B. rapa malformed blossom exhibited the high malformed pollen ratio (Table 1). Four $\mathrm{T}_{1}$ lines 1, 3, 6 and 10 , showed higher malformed pollen radio compared with other lines. Normal blossoms were compared with aberrant blossoms and we found the aberrant blossoms had a higher malformed pollen ratio (Table 1). Three $\mathrm{T}_{0}$ generation lines 1,6 and 10, showed poor seed setting ability when compared to the wild-type (Fig. 4a). Moreover, we found four $T_{1}$ lines 1, 6, 7 and 10 having lower number of siliques and seeds compared with other lines (Fig. 4b). a)

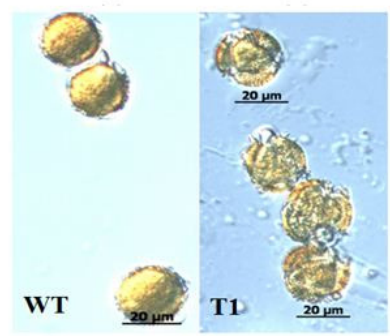

c)

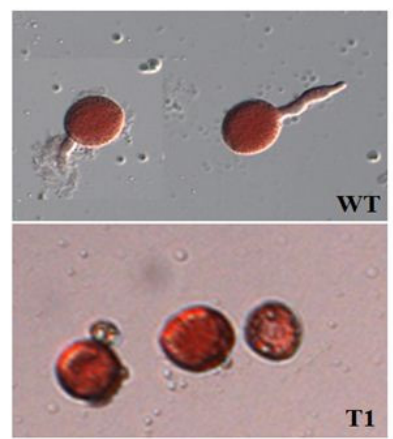

b)

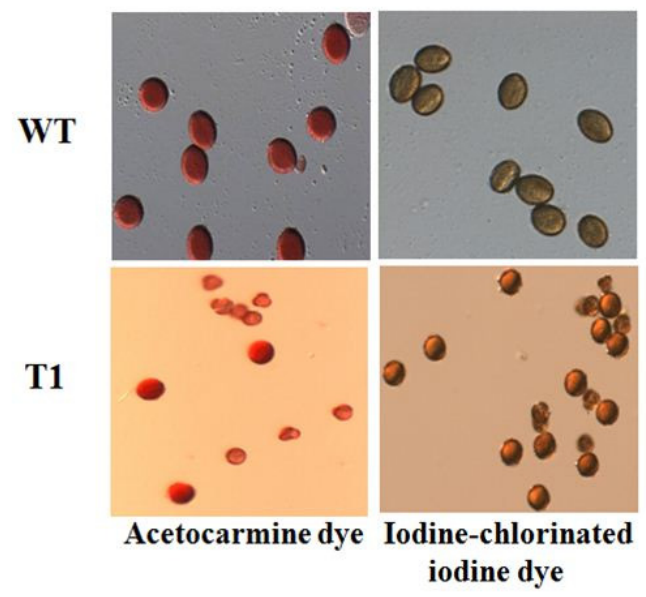

Fig. 3. Pollen viability tests. a) The plasmolysis test was performed to probe the pollen. In hypertonic (25\% glycerol) solution, pollen from orf456 transformants $B$. rapa burst within 10-15 min, while the wild-type pollen grains remained intact even after $24 \mathrm{hr}$. b) Staining test to determine pollen enzymatic activity and membrane integrity. c) In vitro germination assays determine the actual germination ability of pollen under suitable conditions. After 4 hrs of in vitro germination, pollen from wild-type $B$. rapa were able to produce pollen tubes which did not occur in transgenic B. rapa. 


\section{DISCUSSION}

Chimeric orf genes resulting from the rearrangement of a mitochondrial genome are generally thought to be a causal factor in the occurrence of CMS (He et al. 1996). Several transformants containing orf gene constructs, with or without a mitochondrial targeting sequence, exhibited a semi-sterile or male sterile phenotype (He et al. 1996; Wang et al. 2006; Kim et al. 2007; Yamamoto et al. 2008). The failure of mitochondrial expression of novel orfs to induce male sterility is probably due to problems in disruption of mitochondrial membranes (Rhoads et al. 1995; He et al. 1996), effect on ATP synthase function (Bergman et al. 2000; Sabar et al. 2003) and pollen abortion by programmed cell death in transgenic plants. However, there is still little information about how the mitochondrial factor regulates the expression of the nuclear genes involved in male sterility. Previously, to provide definitive evidence that expression of an abnormal mitochondrial gene can interrupt pollen development, a CMS-associated

Table 1. Analysis of malformed pollens ratio of $\mathrm{T}_{1}$ B. rapa plants.

\begin{tabular}{|c|c|c|c|c|c|c|c|c|c|}
\hline \multirow[b]{3}{*}{$\begin{array}{c}\text { Brassica } \\
\text { rapa }\end{array}$} & \multirow{2}{*}{\multicolumn{3}{|c|}{ Blossom }} & \multicolumn{6}{|c|}{ Pollen } \\
\hline & & & & \multicolumn{3}{|c|}{ Normal blossom } & \multicolumn{3}{|c|}{ Malformed blossom } \\
\hline & $\begin{array}{c}\text { Normal } \\
\text { blossome }\end{array}$ & $\begin{array}{c}\text { Malformed } \\
\text { blossom }\end{array}$ & $\begin{array}{c}\text { Malformed } \\
\text { blossom } \\
\text { ratio (\%) }\end{array}$ & $\begin{array}{l}\text { Normal } \\
\text { pollen }\end{array}$ & $\begin{array}{c}\text { Malformed } \\
\text { pollen }\end{array}$ & $\begin{array}{c}\text { Malformed } \\
\text { pollen ratio } \\
(\%)\end{array}$ & $\begin{array}{c}\text { Normal } \\
\text { pollen }\end{array}$ & $\begin{array}{l}\text { Malformed } \\
\text { pollen }\end{array}$ & $\begin{array}{c}\text { Malformed } \\
\text { pollen ratio } \\
(\%)\end{array}$ \\
\hline WT & 25 & 0 & - & 824 & 8 & 0.96 & 915 & 7 & 0.76 \\
\hline $1-5$ & 17 & 6 & 26.09 & 424 & 49 & 10.36 & 417 & 711 & 63.03 \\
\hline $1-7$ & 22 & 4 & 15.38 & 589 & 72 & 10.89 & 885 & 199 & 18.36 \\
\hline $1-8$ & 32 & 1 & 3.03 & 394 & 46 & 10.45 & - & - & - \\
\hline $1-9$ & 22 & 7 & 24.14 & 533 & 218 & 29.03 & 682 & 243 & 26.27 \\
\hline $1-11$ & 25 & 0 & - & 325 & 187 & 36.52 & - & - & - \\
\hline $2-3$ & 25 & 0 & - & 814 & 62 & 7.08 & - & - & - \\
\hline $3-4$ & 20 & 4 & 16.67 & 731 & 213 & 22.56 & 79 & 725 & 90.17 \\
\hline $3-11$ & 31 & 4 & 11.42 & 230 & 349 & 60.28 & 6 & 1291 & 99.54 \\
\hline $3-12$ & 6 & 1 & 14.28 & 229 & 152 & 39.89 & - & - & - \\
\hline $3-15$ & 12 & 4 & 25 & 574 & 78 & 11.96 & 328 & 517 & 61.18 \\
\hline $3-16$ & 79 & 4 & 4.82 & 417 & 57 & 12.03 & 5 & 500 & 99 \\
\hline $4-1$ & 25 & 0 & - & 661 & 46 & 6.51 & - & - & - \\
\hline $4-4$ & 25 & 0 & - & 703 & 57 & 7.5 & - & - & - \\
\hline $4-8$ & 25 & 0 & - & 718 & 49 & 6.39 & - & - & - \\
\hline $4-9$ & 25 & 0 & - & 897 & 42 & 4.47 & - & - & - \\
\hline $6-1$ & 25 & 0 & - & 719 & 34 & 4.52 & - & - & - \\
\hline $6-7$ & 25 & 0 & - & 974 & 29 & 2.89 & - & - & - \\
\hline $6-8$ & 25 & 0 & - & 485 & 40 & 7.61 & - & - & - \\
\hline $6-9$ & 12 & 9 & 42.86 & 636 & 212 & 25 & 355 & 335 & 48.55 \\
\hline $6-10$ & 25 & 0 & - & 712 & 12 & 1.66 & - & - & - \\
\hline $7-1$ & 12 & 1 & 7.69 & 921 & 55 & 5.64 & - & - & - \\
\hline $7-2$ & 13 & 1 & 7.14 & 894 & 210 & 19.02 & - & - & - \\
\hline $7-3$ & 25 & 0 & - & 702 & 27 & 3.7 & - & - & - \\
\hline $7-4$ & 47 & 13 & 21.67 & 528 & 265 & 33.42 & 246 & 87 & 26.13 \\
\hline $7-6$ & 25 & 0 & - & 582 & 192 & 24.81 & - & - & - \\
\hline $10-5$ & 25 & 0 & - & 592 & 45 & 7.06 & - & - & - \\
\hline $10-6$ & 25 & 0 & - & 482 & 72 & 12.99 & - & - & - \\
\hline $10-7$ & 25 & 0 & - & 633 & 48 & 7.05 & - & - & - \\
\hline $10-8$ & 9 & 3 & 25 & 732 & 108 & 12.86 & 312 & 270 & 46.39 \\
\hline $10-9$ & 23 & 1 & 4.17 & 505 & 23 & 4.36 & - & - & - \\
\hline
\end{tabular}


a)

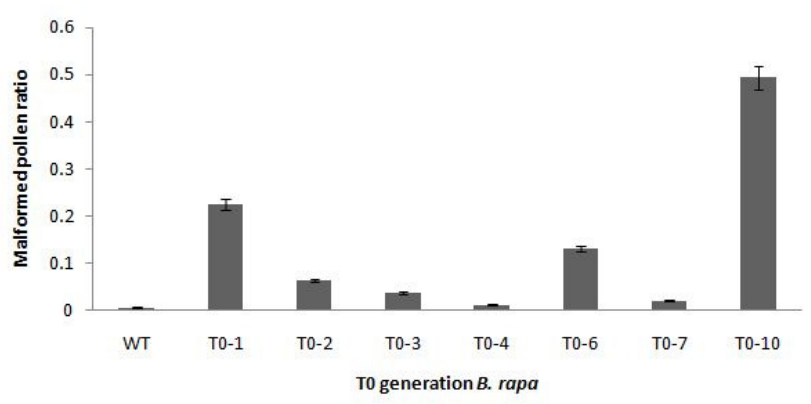

b)

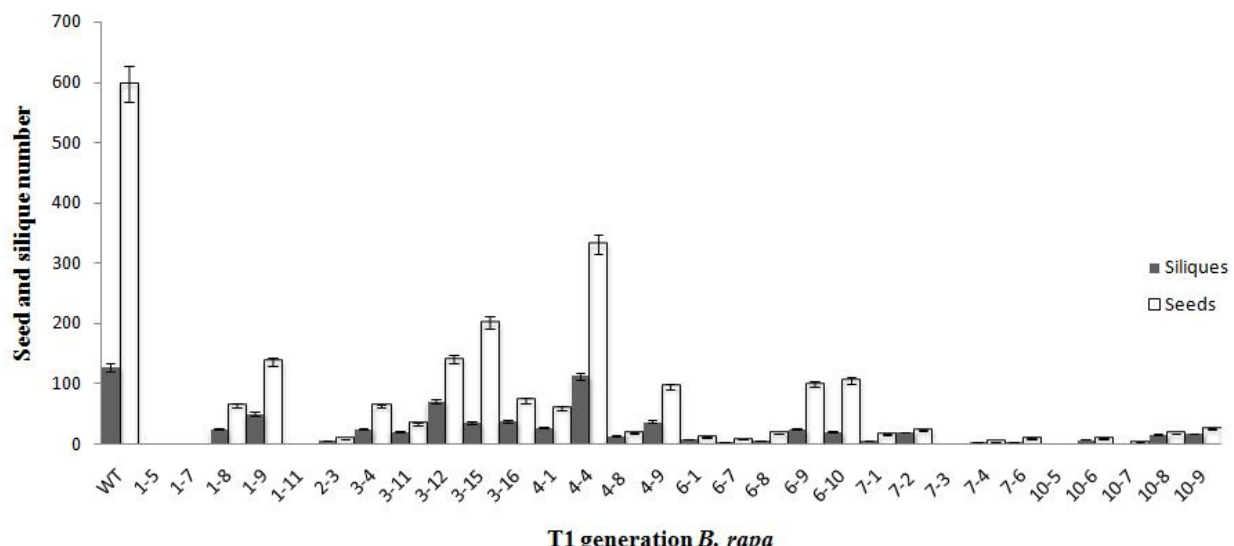

Fig. 4. Analyses of pollen abortion phenotypes in the CMS lines. a) Three $\mathrm{T}_{0}$ lines $(1,6$, and 10) showed semi-sterile phenotype, and higher ratio than other lines. This classification was based on malformed pollen morphology. b) Analysis result of seeds and siliques of wild-type and transgenic $\mathrm{T}_{1} B$. rapa plants.

mitochondrial DNA sequence from chili pepper, orf456, was identified by comparison of cytoplasmic genomes in fertile and CMS lines (Kim et al. 2007). In this paper, orf456 gene was introduced into the Chinese cabbage to test the candidate CMS-associated gene function.

Several attempts have been made to induce CMS by intergeneric hybrid or transformation of CMS-associated genes into Brassica. Ogura (1968) first reported the CMS line of radish, a number of hybrid cultivars have been developed using the Ogura CMS system in many economically important crops. The atp $A$ and $\operatorname{orf} 220$, newly isolated from CMS stem mustard (Brassica juncea. var. tumida Tsen et Lee) (Yang et al. 2010). A chimeric gene orf220-atp2-1 was transformed into in wild-type stem mustard. Kim et al (2007) showed that transgenic Arabidopsis plants carrying a chimeric orf 456 could induce male sterility phenotype which was similar to those observed in CMS chili pepper. In this study we also showed that chimeric orf456 gene induce partial male sterility in B. rapa.
It is thought that the disruption in pollen development is a consequence of mitochondrial dysfunction (He 1996). Furthermore, many genes related to the mitochondrial respiratory complex and pollen development were observed to be down-regulated in transgenic plants and the CMS lines (Yang et al. 2010). To date, functional genes specifically related to pollen development have been well documented. Mutation of any of these genes causes failure of microsporogenesis or abortion of pollen (He ea al. 1996; Kim et al. 2007; Shi et al. 2010; Yang et al. 2010). We used three different approaches to estimate pollen viability: plasmolysis test, staining pollen with dyes and in vitro germination assay (Tuinstra and Wedel 2000). The results of our study indicate that introduction of each of the orf 456 gene constructs resulted in aberrant pollen development and disturbance in function (Fig. 2-4). We compared normal and aberrant blossoms and found higher malformed pollen ratio in aberrant blossoms (Table 1).

In conclusion, the mitochondrial orf 456 gene may 
represent a strong candidate gene involved in CMS in transgenic Chinese cabbage. Nevertheless, how the orf456 gene functions precisely to induce male sterility and its biochemical function remain to be discovered, thus further research is required to explore the signaling pathway of mitochondrial-nuclear genome interactions.

\section{ACKNOWLEDGEMENTS}

This work was supported by a grant (Project No. 609002 -5) from the Screening Center for Disease Resistance Vegetable Crops of the Technology Development Program and a grant (code: 710001-03) from the Vegetable Breeding Research Center through R D Convergence Center Support Program, Ministry for Food, Agriculture, Forestry and Fisheries, Republic of Korea.

\section{REFERENCES}

Bergman P, Edqvist J, Farbos I and Glimelius K. 2000. Male-sterile tobacco is plays abnormal mitochondrial atpl transcript accumulation and reduced floral ATP/ADP ratio. Plant Mol. Biol 42:531-544.

Chase CD. 2007. Cytoplasmic male sterility: a window to the world of plant mitochondrial-nuclear interactions. Trends Genet. 23:81-90.

Chowdhury MJ, Ahmad S, Nazim Uddin M, Quamruzzaman AKM and Patwary MMA. 2010. Expression of Heterosis for Productive Traits in F1 Brinjal (Solanum melongena L.). Hybrids the Agriculturists. 8(2):8-13.

Gómez CC. 1999. Biology of Brassica Coenospecies. Elsevie. 186-189.

Hanson MR and Bentolila S. 2004. Interactions of mitochondrial and nuclear genes that affect male gametophyte development. Plant Cell. 16:154-169.

He S, Abad AR, Gelvin SB and Mackenzie SA. 1996. A cytoplasmic male sterility-associated mitochondrial protein causes pollen disruption in transgenic tobacco. Proc Natl Acad Sci USA. 93:11763-11768.

Hirai M and Matsumoto S. 2007. Brassica rapa. Genome Mapping and Molecular Breeding in Plants. Springer-Verlag Berlin, Heidelberg. 5:185-190.

Kim DH and Kim BD. 2006a. The organization of mitochondrial atp6 gene region in male fertile and CMS lines of pepper (Capsicum annuum L.). Curr. Genet. 49:59-67.

Kim DH, Kang JG and Kim BD. 2007. Isolation and characterization of the cytoplasmic male sterility-associated orf456 gene of chili pepper (Capsicum annuиm L.). Plant Mol Biol. 63:519-532.

Kim DH, Kang JG, Kim SJ and Kim BD. 2001. Identification of cox2 and atp6 regions as associated to CMS in Capsicum annuum by using RFLP and long accurate PCR. Hortic Sci. 42:121-127.

Linke B and Börner T. 2005. Mitochondrial effects on flower and pollen development. Mitochondrion. 5:389-402.

Li XN, Nirala R, Vignesh D, Choi SR, Hur YK, Nou LS, Yoon MK and Lim YP. 2013. Quantitative trait loci mapping in Brassica rapa revealed the structural and functional conservation of genetic loci governing morphological and yield component traits in the $\mathrm{A}, \mathrm{B}$, and $\mathrm{C}$ subgenomes of Brassica species. DNA Research. 20:1-16.

Nassar NMA, Santos ED and David S. 2000. The transference of apomixis genes from Manihot. neusana Nassar to Cassava, M. eculenta Crantz. Hereditas. 132:167-170.

Ogura H. 1968. Studies on the new male sterility in Japanese radish with specil reference to utilization of this sterility towards the practical raising of hybide seeds. Mem. Fac. Agr.Kagoshima Univ. 6:39-78.

Prince JP, Zhang W, Radwanski ER and Kyle MM. 1997. A versatile and high-yielding protocol for the preparation of genomic DNA from Capsicum spp. (pepper). Hortiscience. 32:937-939.

Quijada P, Wang XW, Hirai JC and Kole C. 2007. Oil seeds. Genome Mapping and Molecular Breeding in Plants. Springer Berlin Heidelberg. 2:211-263.

Rhoads DM, Levings CS and Siedow JN. 1995. URF13, a ligand-gated, pore-forming receptor for T-toxin in the inner membrane of cms-T mitochondria. J. Bioenerg. Biomembr. 27:437-445.

Rich TCG. 1991. Crucifers of Great Britain and Ireland. Botanical Society of the British Isles, London. 36.

Sabar M, Gagliardi D, Balk J and Leaver CJ. 2003. ORFB is a subunit of F1F0-ATP synthase: Insight into the basis of cytoplasmic male sterility in sunflower. EMBO Rep. 4:1-6.

Schnabel PS and Wise RP. 1998. The molecular basis of cytoplasmic male-sterility and fertility rest oration. Trends Plant Sci. 3:175-180.

Shi Sl, Ding D, Mei SY and Wang JB. 2010. A comparative light and electron microscopic analysis of microspore 
and tapetum development in fertile and cytoplasmic male sterile radish. Protoplasma. 241:37-49.

Tuinstra MR and Wedel J. 2000. Estimation of pollen viability in grain sorghum. Crop Sci. 40:968-970.

Wang ZH, Zou YJ, Li XY, Zhang QY, Chen L, Wu H, Su DH, Chen YL, Guo JX, Luo D, Long YM, Zhong Y and Liu YG. 2006. Cytoplasmic male sterility of rice with boro II cytoplasm is caused by a cytotoxic peptide and is restored by two related PPR motif genes via distinct modes of mRNA silencing. Plant Cell. 18:676-687.

Yang JH, Liu XY, Yang XD and Zhang MF. 2010.
Mitochondrially-targeted expression of a cytoplasmic male sterility-associated orf220 gene causes male sterility in Brassica juncea. BMC plant biology. 10:231.

Yang JH and Zhang MF. 2007. Molecular genetics of mitochondrial respiratory/ATP-related genes in relation to cytoplasmic male-sterility of higher plants. Gene Genomes and Genomics. 1:21-26.

Yamamoto MP, Shinada H, Onodera Y, Komaki C, Mikami T and Kubo T. 2008. A male sterility-associated mitochondrial protein in wild beets causes pollen disruption in transgenic plants. Plant J. 54:1027-1036. 